Research Paper

\title{
Complete Disaggregation of MCF-7-derived Breast Tumour Spheroids with Very Low Concentrations of $\alpha$-Mangostin Loaded in CD44 Thioaptamer-tagged Nanoparticles
}

\author{
Francesca Bonafè, Claudia Pazzini, Silvia Marchionni, Carlo Guarnieri, Claudio Muscari ${ }^{\bowtie}$ \\ Department of Biomedical and Neuromotor Sciences (DIBINEM), University of Bologna, Via Irnerio 48, 40126 Bologna, Italy. \\ $\triangle$ Corresponding author: Claudio Muscari, Department of Biomedical and Neuromotor Sciences, University of Bologna, Via Irnerio 48,40126 Bologna, Italy. \\ Tel: +39 0512091245 Fax: +39 0512091224 e-mail address: claudio.muscari@unibo.it \\ (C) Ivyspring International Publisher. This is an open access article distributed under the terms of the Creative Commons Attribution (CC BY-NC) license \\ (https://creativecommons.org/licenses/by-nc/4.0/). See http://ivyspring.com/terms for full terms and conditions.
}

Received: 2018.06.26; Accepted: 2018.10.10; Published: 2019.01.01

\begin{abstract}
Background: $\alpha$-Mangostin $(\alpha M G)$ is a natural substance that exerts a wide range of antitumor effects. Recently, we described that free $\alpha M G$ was able to dissociate multicellular tumour spheroids (MCTSs) generated from breast carcinoma cells and to reduce their cellular viability and motility. Here, $\alpha M G$ was encapsulated into lipidic nanoparticles (NPs), conjugated or not to a CD44 thioaptamer, and the anticancer action evaluated against MCF-7 breast MCTSs.

Methods: NPs containing $\alpha M G$ were formulated with a core of polylactic-co-glycolyc acid. Some of them were decorated with a CD44 thioaptamer using as catalysts 1-ethyl-3- (3-dimethylaminopropyl) carbodiimide and N-hydroxysuccinimide. Both size and density of MCF-7-derived MCTSs were monitored during $72 \mathrm{~h}$ of treatment with NPs carrying $0.1,0.5$ and $1.0 \mu \mathrm{g} / \mathrm{ml}$ final concentrations of $\alpha M G$. MCTSs were cultured on Matrigel or gelatine to better simulate the extracellular environment.

Results: The NPs without thioaptamer and conveying $0.1 \mu \mathrm{g} / \mathrm{ml} \alpha M G$ caused a significant dissociation of the MCTSs grown in gelatine after $24 \mathrm{~h}$ of treatment $(p<0.01)$. The most significant disaggregation of MCTSs was obtained using NPs carrying $0.5 \mu \mathrm{g} / \mathrm{ml} \alpha M G(p<0.01)$. A similar dissociating effect was observed when MCTSs were cultured in Matrigel under the same conditions for $48-72 \mathrm{~h}$. By contrast, only concentrations over $1.0 \mu \mathrm{g} / \mathrm{ml}$ of free $\alpha M G$ were able to provoke a damage to MCTSs, consisting in a substantial reduction in their size $(p<0.05)$. Since the MCTS dissociation induced by $\alpha M G$-loaded NPs occurred only in the presence of Matrigel or gelatine, an impairment of cell contacts to collagen fibres was likely responsible of this effect. Finally, the treatment of MCTSs with $\alpha$ MG-loaded NPs that were conjugated to the CD44 thioaptamer caused a similar decrease in density but a lower expansion of the spheroid, suggesting that a significant number of cells were died or arrested in cycle.

Conclusion: Very low concentrations of $\alpha M G$ delivered by lipidic NPs are sufficient to provoke a substantial disaggregation of MCF-7 MCTSs that involves cell-to-collagen contacts. Similarly, the treatment of MCTSs with NPs conjugated to a CD44 thioaptamer leads to MCTS dissociation but through a more damaging action that causes also a reduction in cell number.
\end{abstract}

Key words: $\alpha$-mangostin, multicellular tumour spheroid, breast cancer cell line, MCF-7, nanoparticle, thioaptamer.

\section{Introduction}

$\alpha$-Mangostin $(\alpha \mathrm{MG})$, a xanthone that is contained in large amount in Garcinia mangostana Linn, has been demonstrated to possess several antitumor properties under in vitro and in vivo conditions [1]. The wide range of pharmacological activities of $\alpha \mathrm{MG}$ and the low frequency of its adverse 
effects have contributed to propose this natural substance as an adjuvant in cancer therapy [2]. Recently, we described novel harmful effects of $\alpha M G$ against three-dimensional (3D) multicellular tumour spheroids (MCTSs) generated by MDA-MB-231 human breast cancer cells, such as disaggregation and size reduction of the tumour bulk that were paralleled by a decrease in cell viability and motility [3]. Instead of cell monolayers, MCTSs are usually preferred as a laboratory model for pharmacological investigations because better simulate the 3D architecture of solid tumours, especially those regions that are not well perfused due to an inefficient vascularization [4]. The thickness of MCTSs generates a gradient of nutrients, oxygen and waste compounds from the surface to the core that affects not only biological functions but also cell response to drugs [5]. In particular, the inner layers of MCTSs become hypoxic when the radius exceeds $120 \mu \mathrm{m}$ [6]. Moreover, under hypoxic conditions tumour cells can undergo a selection that makes them more resistant to various stresses and that generates cancer stem cells (CSCs) [7, 8]. MCTSs can be also useful to study drug diffusion since it depends on the thickness of the tumour and the features of cell-to-cell and cell-to-matrix contacts [9].

Bioavailability, pharmacokinetics and pharmacodynamics of antitumor drugs are fields on continuous improvement. One of the most appealing strategies that have been investigating is the use of nanoparticles (NPs) as a vehicle for intravenous infusion [10]. NPs in the range of $100 \mathrm{~nm}$ diameter and covered by lipophilic/polyethylene glycol layers are not recognized by the reticular endothelial system and hence the lifespan of the transported drug in the body is increased [11]. In addition, according to the "enhanced permeability and retention" (EPR) effect, small NPs preferentially concentrate into the tumour mass rather than in normal tissues [12]. This condition seems to occur thanks to the synergistic process of NP leakage from large capillary gaps and the subsequent tissue entrapment of NPs due to a poor lymphatic drainage. Tumour cell selectivity can be further improved by conjugating NPs to ligands that target exclusive, or more largely expressed, superficial molecules $[13,14]$. In particular, aptamers are usually considered as superior ligands in respect to antibodies because they are not degraded by proteases and can become more resistant to the nuclease attack through simple modifications in their phosphate backbone [15]. Moreover, a receptor-mediated process accelerates the entry of drugs into the cell when they are carried by ligand-conjugated NPs [16]. Therefore, NPs targeting specific tumour cells can be considered as a suitable tool to reduce the dosage of the drug cargo and, therefore, the occurrence of adverse effects of chemotherapy.

According to these concepts, we generated MCTSs by a MCF-7 breast carcinoma cell line and the antitumor effects of $\alpha \mathrm{MG}$, as a free compound or encapsulated in lipidic NPs, were evaluated. We found that very low concentrations of $\alpha M G$ delivered by NPs caused a significant reduction in spheroid compactness, without increasing cell invasiveness. Since MCF-7 cells largely express CD44, the antitumor activity of $\alpha \mathrm{MG}$-loaded NPs conjugated to a CD44 thioaptamer was also investigated.

\section{Materials and Methods}

\section{Materials}

Reagents were purchased from Sigma-Aldrich (St. Louis, MO, USA), unless otherwise stated.

\section{MCF-7 cell monolayer}

MCF-7 human breast carcinoma cell line (the European Collection of Authenticated Cell Cultures, ECAAC) were expanded in culture flasks under standard conditions $\left(37^{\circ} \mathrm{C}, 5 \% \mathrm{CO}_{2}, 95 \%\right.$ humidity) or subjected to a low oxygen tension $\left(1 \% \mathrm{O}_{2}, 94 \% \mathrm{~N}_{2}, 5 \%\right.$ $\mathrm{CO}_{2}$ ). Cells were cultured in complete Dulbecco's modified Eagle medium (DMEM), containing 2\% fetal calf serum (v/v), $100 \mathrm{U} / \mathrm{ml}$ penicillin and $100 \mu \mathrm{g} / \mathrm{ml}$ streptomycin. The culture medium was routinely replaced twice a week. For cell expansion, subconfluent cells were detached using a solution of $0.05 \%$ trypsin in $0.53 \mathrm{mM}$ EDTA. MCF-7 cells were cultured also as monolayers on 96-well flat-bottomed plates at the density of $1 \times 10^{4}$ cells/well.

\section{Generation and morphological analysis of MCTSs}

For the initial characterization of the spheroids, MCF-7 cells were seeded in ultra-low attachment (ULA) 6-well flat-bottomed plates (Corning; Sigma-Aldrich) at densities ranging from $1 \times 10^{3}$ to $2 \times 10^{4}$ cells $/ \mathrm{ml}$. The culture medium was serum-free DMEM/F12 (1:1 v/v) containing 2\% B27 (ThermoFisher Scientific, Waltham, MA, USA), 20 $\mathrm{ng} / \mathrm{ml}$ epidermal growth factor (EGF, Peprotech, Rocky Hill, NJ, USA), $20 \mathrm{ng} / \mathrm{ml}$ basic fibroblast growth factor (bFGF, Peprotech), $100 \mathrm{U} / \mathrm{ml}$ penicillin, and $100 \mu \mathrm{g} / \mathrm{ml}$ streptomycin (MCTS medium). To perform a high throughput screening, $200 \mu \mathrm{l}$ of cell suspension in MCTS medium was seeded on each well of ULA 96-well round-bottomed plates (Corning) and to encourage cell aggregation, the plates were centrifuged at $100 \mathrm{~g}$ for $3 \mathrm{~min}$. Under this condition, spheroids of diameter ranging between 250 and 300 $\mu \mathrm{m}$ were generated after three days. Then, some 
MCTSs were treated with different concentrations of aMG dissolved in $0.1 \%(\mathrm{v} / \mathrm{v})$ dimethylsulfoxide (DMSO), while control MCTSs were exposed only to the vehicle.

Images were captured using an inverted microscope (IX50, Olympus Italia, Segrate, Italy), equipped with an Olympus camera, and imported into Image-J software (Fiji, http://imagej.nih.gov). Using the graphic utilities of Image-J, the largest (equatorial) border of each spheroid was manually drawn and the pseudo-circular area of its phase-contrast image was calculated. After background subtraction, the MCTS density was measured using the "mean grey" command of the software applied to the 8-bit inverted images of each spheroid. This parameter provided the grey half-tone intensity-to-area ratio of the pseudo-circular images of MCTSs. Morphological measurements were performed each day of treatment and expressed as percentage of those obtained at day 3 after cell seeding (100\%). Some spheroids grew for three days on ULA plates and then were transferred to adherent 96-well flat-bottomed plates (Corning) that were coated with $100 \mu \mathrm{l}$ of $0.1 \%(\mathrm{w} / \mathrm{v})$ gelatine or Matrigel (Corning) for better simulating the extracellular matrix (ECM) environment of solid tumours [17].

\section{Cell viability assay}

MCF-7 cells at the density of $1 \times 10^{4}$ cells/well were seeded on adherent 96-well flat-bottomed plates and cultured as monolayers in complete medium for 48 h [18]. Then, PrestoBlue Cell Viability Reagent 10X solution (ThermoFisher Scientific) was added in each well at a $10 \%$ final concentration. Fluorescence was measured at $530 \mathrm{~nm}$ excitation and $590 \mathrm{~nm}$ emission on a Wallac VICTOR ${ }^{2}$ multiwell plate reader (Perkin Elmer, Milan, Italy) $4 \mathrm{~h}$ after dye addition.

\section{Production of NPs}

Lipid-polymer combinational nanoparticles were synthesized from polylactic-co-glycolic acid (PLGA), soybean lecithin and 1,2-diasteroylglycero-3-phosphoethanolamine-N-carboxy(polyethy lene-glycol)2000 (DSPE-PEG2000-COOH) using a nanoprecipitation technique combined with self-assembly [19]. PLGA (50:50, M.W. 30-70 kDa) was first dissolved in acetonitrile at a concentration of 1 $\mathrm{mg} / \mathrm{ml}$. Lecithin and DSPE-PEG2000-COOH were dissolved with a 7:3 molar ratio in $4 \%$ ethanol aqueous solution at $15 \%$ of the PLGA polymer weight and heated to $65{ }^{\circ} \mathrm{C}$. Then, the PLGA/acetonitrile solution was added to the lipid/aqueous solution in drop-wise manner, followed by vortexing for $3 \mathrm{~min}$. $\alpha M G$ was added to the PLGA solution in the ratio 1:10 $(\mathrm{w} / \mathrm{w})$ relative to the polymer. The solution was then subjected to indirect sonication for $5 \mathrm{~min}$ in ice-cold water. The NPs were allowed to self-assemble and the organic solvent to evaporate with continuous stirring for $3.5 \mathrm{~h}$. The remaining organic solvent and the free molecules were removed by washing the NP solution two times in ethanol/water and the third time in distilled water using an Amicon Ultra-4 centrifugal filter with a molecular weight cut-off of $10 \mathrm{kDa}$ (Millipore; Sigma-Aldrich). The NPs were sonicated again, filtered by $200 \mathrm{~nm}$ cut-off (Corning), and divided in two aliquots of $1 \mathrm{ml}$ each. An aliquot was air dried for about $1 \mathrm{~h}$, weighed, and dissolved in acetonitrile plus 30\% phosphate buffer saline (PBS), $\mathrm{pH}$ 7.2, for the spectrophotometric measurement of drug encapsulation (peak of absorbance of $\alpha \mathrm{MG}$ at $320 \mathrm{~nm}$ ). The second aliquot of $1 \mathrm{ml}$ was immediately used to perform the conjugation with the aptamer. The remained suspension of NPs was stored at $-20^{\circ} \mathrm{C}$. Fluorescent nanoparticles were also prepared by adding $10 \mu \mathrm{l}$ of the fluorochrome Nile Red at the concentration of $1 \mathrm{mg} / \mathrm{ml}$.

\section{Conjugation of the thioaptamer to NPs}

A DNA thioaptamer that specifically binds to CD44 according to the formulation TA6 described by Somasunderam et al. [20] was synthesized by Trilink Biotechnologies (San Diego, CA, USA). The 73-mer oligonucleotide is a back bone-modified aptamer in which the non-bridging phosphoryl oxygens are substituted with sulphur. This change of structure renders the aptamer more resistant to the cellular degradation exerted by nucleases. The thioaptamer (M.W. 24,229.0) was linked to an amino group at the $5^{\prime}$ end to allow the carboxyl group of DSPE-PEG2000-COOH to form a carbamide covalent bond. For this purpose, we used the two catalysts 1-ethyl-3- (3-dimethylaminopropyl) carbodiimide (EDC) and N-hydroxysuccinimide (NHS) according to the manufacturer's instructions (ThermoFisher Scientific). Briefly, NPs (10 mg) were dissolved in $1 \mathrm{ml}$ of distilled water, filtered with an Amicon Ultra-4 10 $\mathrm{kDa}$ (Millipore) and resuspended in $1 \mathrm{ml}$ of buffered $0.1 \mathrm{M}$ 2-(N-morpholino)ethanesulfonic acid, $0.5 \mathrm{M}$ $\mathrm{NaCl}, \mathrm{pH} 6.0$, containing a molar concentration of EDC and NHS 10-fold and 25-fold higher than DSPE-PEG2000-COOH, respectively. NP suspension was shacked gently at room temperature for $15 \mathrm{~min}$. The resulting NHS-activated NPs were washed twice in distilled water with Amicon Ultra-4 10 kDa filters, resuspended in $1 \mathrm{ml}$ PBS and conjugated to 3 nmoles of thioaptamer corresponding to a 1:100 ratio with respect to $0.85 \mathrm{mg}$ DSPE-PEG2000-COOH used for the synthesis of $10 \mathrm{mg}$ NPs. To this purpose, $30 \mu \mathrm{l}$ of 100 $\mu \mathrm{M}$ thioaptamer in PBS was added to $1 \mathrm{ml}$ PBS containing $10 \mathrm{mg}$ NHS-activated NPs and stirred at 
room temperature for $2 \mathrm{~h}$. To remove the free thioaptamer, the final solution was washed three times in distilled water, using the Amicon Ultra-4 10 $\mathrm{kDa}$ filter, and the NPs resuspended in distilled water at the concentration of $10 \mathrm{mg} / \mathrm{ml}$.

\section{Characterization and size measurement of NPs}

NP size was measured by tuneable resistive pulse sensing (TRPS) using the qNano Nanoparticle Analyser V2.0 (iZON Science, Christchurch, New Zealand) equipped with a fluid cell module of $300 \mathrm{~nm}$ nanopores (NP300) and operated by the V3.1 Control Suite software.

The ability of NPs, free or conjugated to the thioaptamer, to enter cells was evaluated by phase contrast and fluorescence microscopy (Olympus IX50) using $\mathrm{CD}_{4} 4^{+}$human bone marrow mesenchymal stromal cells (BM-MSCs; TebuBio, Magenta, Italy) at the density of $4 \times 10^{3} / \mathrm{ml}$. NPs were also observed by scanning electron microscopy (JSM-5200; JEOL, Tokyo, Japan).

\section{Western blotting analysis}

MCF-7 cells were homogenized in a glass tissue grinder in $20 \mathrm{mM}$ HEPES, $\mathrm{pH} 7.5$, containing $5 \mathrm{mM}$ dithiothreitol, 2 mM EDTA, 0.1\% CHAPS detergent, $0.1 \%$ Triton $\mathrm{X}-100$, and protease inhibitors; then, they were centrifuged at $15,000 \mathrm{~g}$ for $15 \mathrm{~min}$. The supernatant was diluted in loading buffer ( $2 \%$ SDS, $5 \%$ glycerol, $0.002 \%$ bromophenol blue, $4 \%$ $\beta$-mercaptoethanol in $0.25 \mathrm{M}$ Tris- $\mathrm{HCl}, \mathrm{pH} 6.8$ ) and denatured by boiling for $3 \mathrm{~min}$. Aliquots corresponding to $80 \mu \mathrm{g}$ protein were analysed by SDS-PAGE $(7.5 \%$ gel). Proteins were transferred onto a nitrocellulose membrane for $1 \mathrm{~h}$. This membrane was then saturated with $5 \%$ dry milk for $1 \mathrm{~h}$, washed with Tris-buffered saline, and probed overnight at $4^{\circ} \mathrm{C}$ with the specific primary antibodies (1:500 mouse monoclonal anti-HIF-1 $\alpha$ and 1:1,000 mouse monoclonal anti- $\beta$-actin; Santa Cruz Biotechnology, Heidelberg, Germany). The membrane was then incubated for $1 \mathrm{~h}$ with the secondary antibody $(1: 2,500$ horseradish peroxidase-conjugated species-specific anti-IgG; Santa Cruz Biotechnology).

\section{Statistical analysis}

Values are expressed as mean \pm standard error of the mean (SEM). Linear regression analysis and one-way analysis of variance (ANOVA) followed by Bonferroni multiple-comparison test were performed using GraphPad Prism 4.0 software (San Diego, CA, USA). $\mathrm{P}<0.05$ was considered statistically significant.

\section{Results}

\section{Viability of MCF-7 cells treated with free $\alpha$ MG}

MCF-7 cells at the density of $1 \times 10^{4}$ cells/well were cultured as monolayers on 96-well flat-bottomed plates under normoxic conditions. The treatment with $0.1-20 \mu \mathrm{g} / \mathrm{ml} \alpha \mathrm{MG}$ for $48 \mathrm{~h}$ caused a bi-modal and dose-dependent decrease in cell viability. Figure 1 shows that cells were markedly damaged by concentrations of $\alpha \mathrm{MG}$ up to $1.0 \mu \mathrm{g} / \mathrm{ml}$, while higher doses up to $20 \mu \mathrm{g} / \mathrm{ml}$ led to a less accentuated drop in viability.

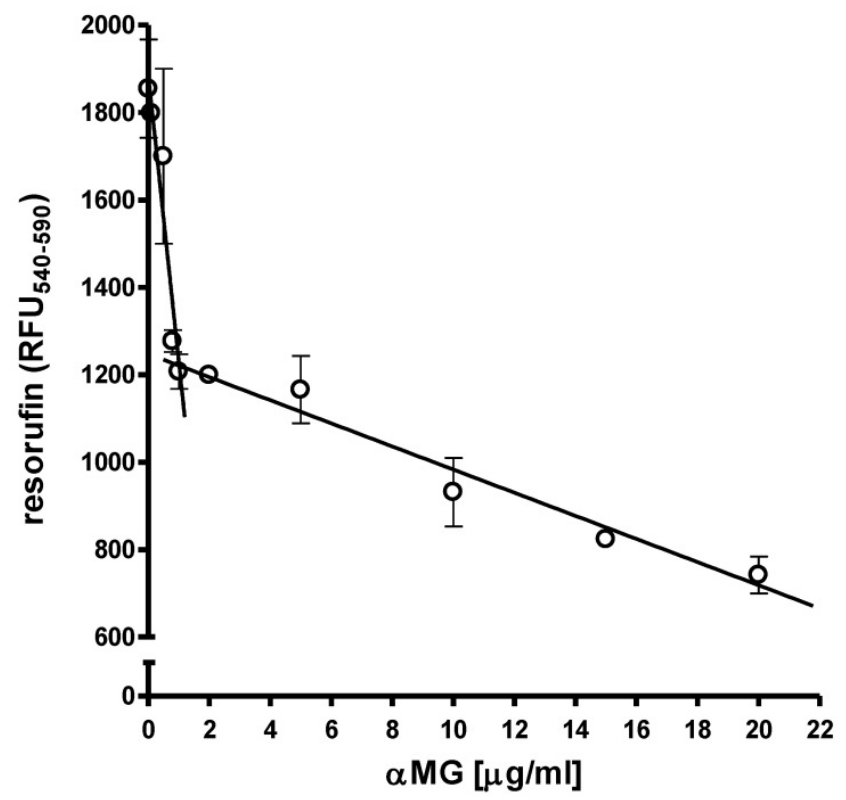

Figure 1. Effects of free $\alpha M G$ on the MCF-7 cell monolayer. The viability of $1 \times 10^{4}$ MCF-7 cells was reduced after treatment with free $\alpha M G$ for $48 \mathrm{~h}$ in a dose-dependent manner. The cells were greatly affected by $0.1-1 \mu \mathrm{g} / \mathrm{ml} \alpha M G$ that caused a sharp decrease in their viability. A further damage to cells was observed using higher concentrations of $\alpha M G$, although their responsiveness was reduced. Values were subjected to linear regression analysis and are expressed as mean \pm SEM of duplicated experiments.

\section{Effects of free $\alpha M G$ against MCTSs}

As preliminary characterizing set of experiments, MCTSs were produced in ULA 6-well plates by seeding $1 \mathrm{x}, 5 \mathrm{x}, 10 \mathrm{x}$ and $20 \times 10^{3}$ MCF-7 cells $/ \mathrm{ml}$ and the increasing size of the spheroids with cell density was verified (Figure 2a). Then, to obtain a high-throughput availability of MCTSs, a single spheroid per well was grown in ULA round-bottomed 96-well plates for 15 days (Figure $2 b$ ). The seeding density of $1 \times 10^{4}$ cells/well was chosen because represented the best condition to obtain spheroids that were not too large for the limited size of the well but enough compact and well-shaped to perform appropriate morphological investigations. 

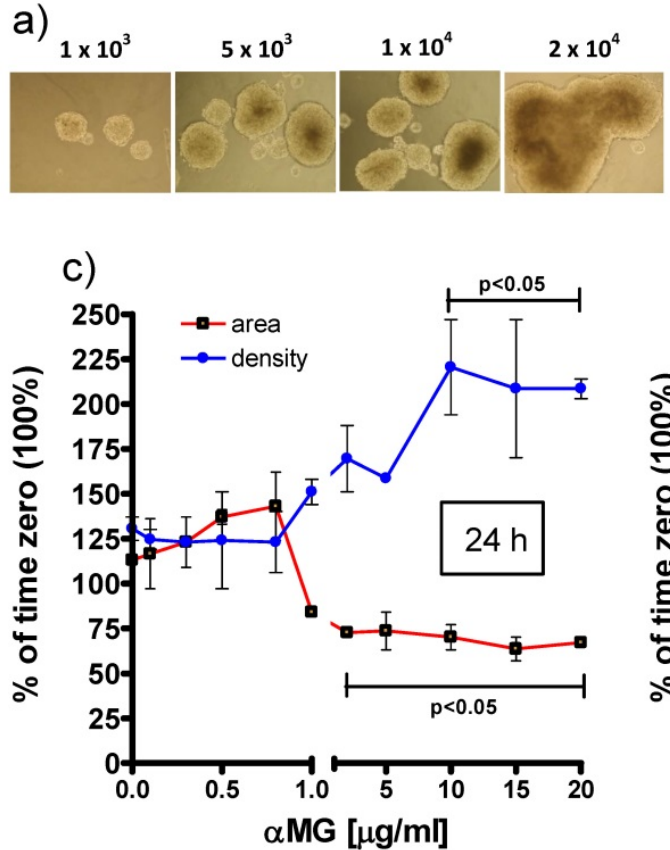

e)

0.0 (untreated)

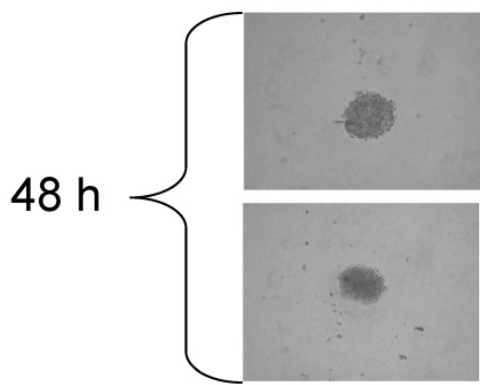

1.0

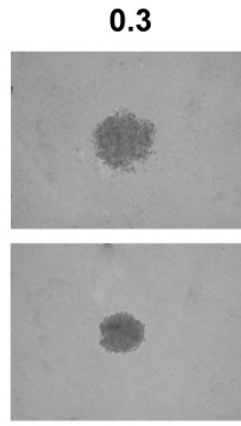

5.0 b)

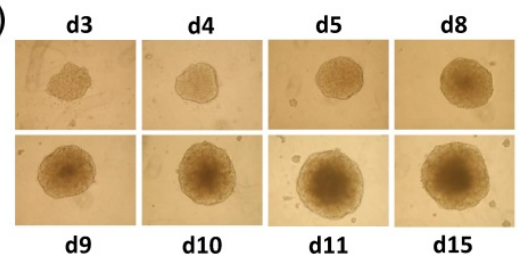

d)

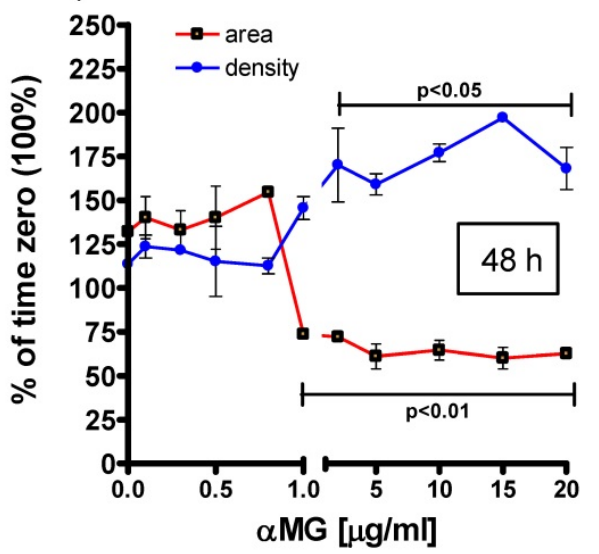

0.5

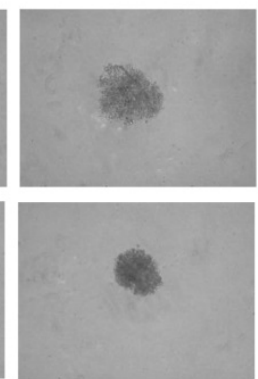

10
0.8

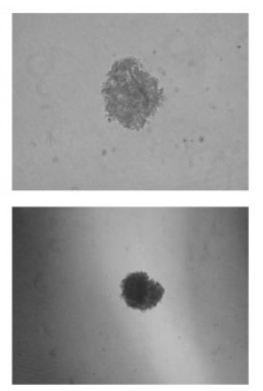

20

Figure 2. Effects of free $\alpha M G$ on MCTS size and density. (a) MCF-7 cells seeded at 1x, $5 x, 10 x$ and $20 \times 10^{3} \mathrm{cells} / \mathrm{ml}$ in ULA 6-well flat-bottomed plates generated MCTSs of increasing size after 7 days. The spheroids merged into larger aggregates at the highest cell density (magnification: 50X). (b) The images show a single MCTS per well that was grown in ULA 96-well round-bottomed plates for 15 days (representative images of triplicate experiments). The optimized seeding density of $1 \times 10^{4}$ cells/well allowed to obtain 3D bodies with a circular profile and homogeneous cellular distribution (magnification: $50 \mathrm{X}$ ). The spheroids treated with free $\alpha M G$ for $24 \mathrm{~h}$ (c) and $48 \mathrm{~h}$ (d) were negatively affected by doses higher than $0.8-1.0 \mu \mathrm{g} / \mathrm{ml}(\mathrm{n}=2)$. MCTSs generated in the presence of 1.0-20 $\mu \mathrm{g} / \mathrm{ml}$ free $\alpha \mathrm{MG}$ showed a smaller area and a parallel increase in density with respect the untreated MCTSs. (e) Representative phase-contrast images of the MCTSs treated for $48 \mathrm{~h}$ with increasing doses of free $\alpha M G$ (magnification: $50 \mathrm{X}$ ). The numerical values correspond to the concentrations of $\alpha M G$ expressed as $\mu \mathrm{g} / \mathrm{ml}$. At the highest dose, a darker region of cellular necrosis is clearly visible.

The treatment with free $\alpha M G$ produced damages to the spheroids that were shown as changes in equatorial area and density (Figure 2c, 2d). The lowest concentrations of $\alpha \mathrm{MG}$ that significantly reduced the MCTS area were $3 \mu \mathrm{g} / \mathrm{ml}$ and $1 \mu \mathrm{g} / \mathrm{ml}$, administered for $24 \mathrm{~h}(\mathrm{p}<0.05)$ and $48 \mathrm{~h}(\mathrm{p}<0.01)$, respectively. Conversely, the MCTS density underwent a parallel increase that reached statistical significance after treatment with $\alpha \mathrm{MG}$ at the concentrations of 10 $\mu \mathrm{g} / \mathrm{ml}$ for $24 \mathrm{~h}(\mathrm{p}<0.05)$ and $3 \mu \mathrm{g} / \mathrm{ml}$ for $48 \mathrm{~h}(\mathrm{p}<$ $0.05)$. The irregular edges of the MCTSs and the homogenous distribution of their density observed at the highest doses (Figure 2e) were considered as further signs of $\alpha \mathrm{MG}$ toxicity.

\section{Characterization and cell uptake of NPs}

The mean diameter of NPs was $227.0 \pm 88 \mathrm{~nm}$ and $174.0 \pm 29 \mathrm{~nm}$ before and after filtration, respectively (Figure $3 a, 3 b$ ). Both diameter and size distribution of NPs were consistent with the images obtained by SEM (Figure 3c). The fluorescent dye Nile Red was loaded in NPs to trace their uptake inside cells. BM-MSCs were chosen to better perform this test because they are larger than MCF-7 after adhesion on plates of polystyrene. BM-MSCs were incubated with NPs and observed by a combination of phase contrast and fluorescence microscopy. The process of NP incorporation into cells was effective after $24 \mathrm{~h}$ (Figure $3 \mathrm{~d}, 3 \mathrm{e}$ ) and larger aggregates of NPs were generated after $48 \mathrm{~h}$ of incubation (Figure $3 \mathrm{f}$ ). 
a)

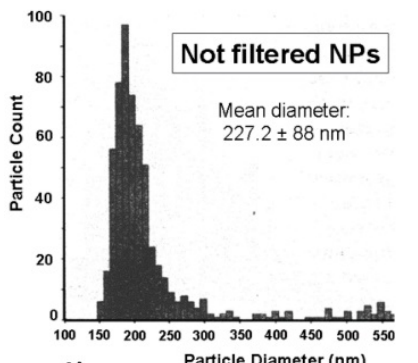

d)

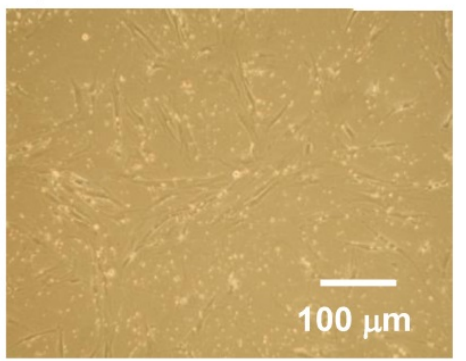

b)

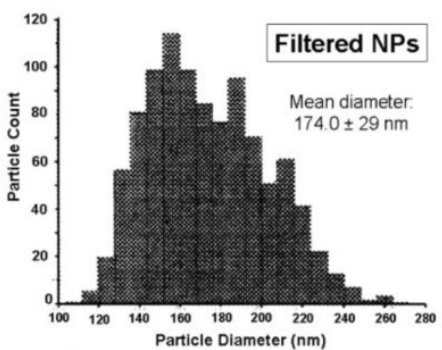

e)

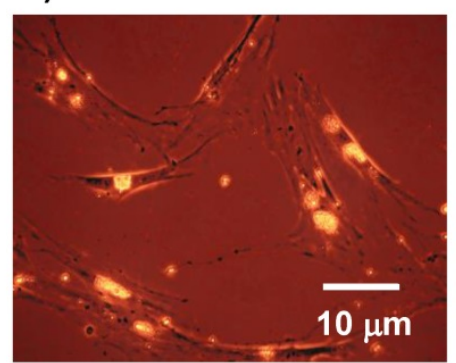

c)

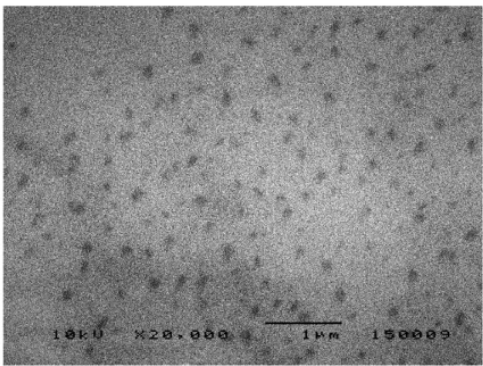

f)

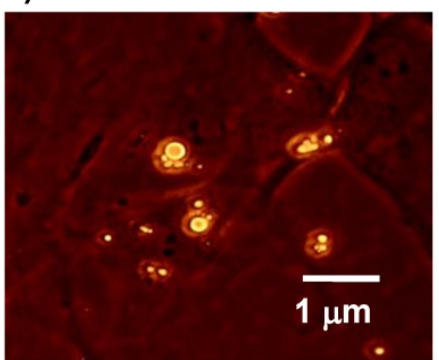

Figure 3. Characterization and cell uptake of NPs. (a) The size distribution of NPs measured just after their production was $150-380$ nm. (b) The range of NP diameter was restricted to $110-260 \mathrm{~nm}$ after filtration, with a mean value of $174.0 \pm 29 \mathrm{~nm}$. (c) NP size and distribution were consistent with the images obtained by SEM. (d, e) BM-MSCs were incubated with Nile Red-loaded NPs and contemporary observed by phase contrast and fluorescence microscopy after 24 h. (f) Most NPs fused into larger aggregates after $48 \mathrm{~h}$. Images are representative of duplicate experiments.

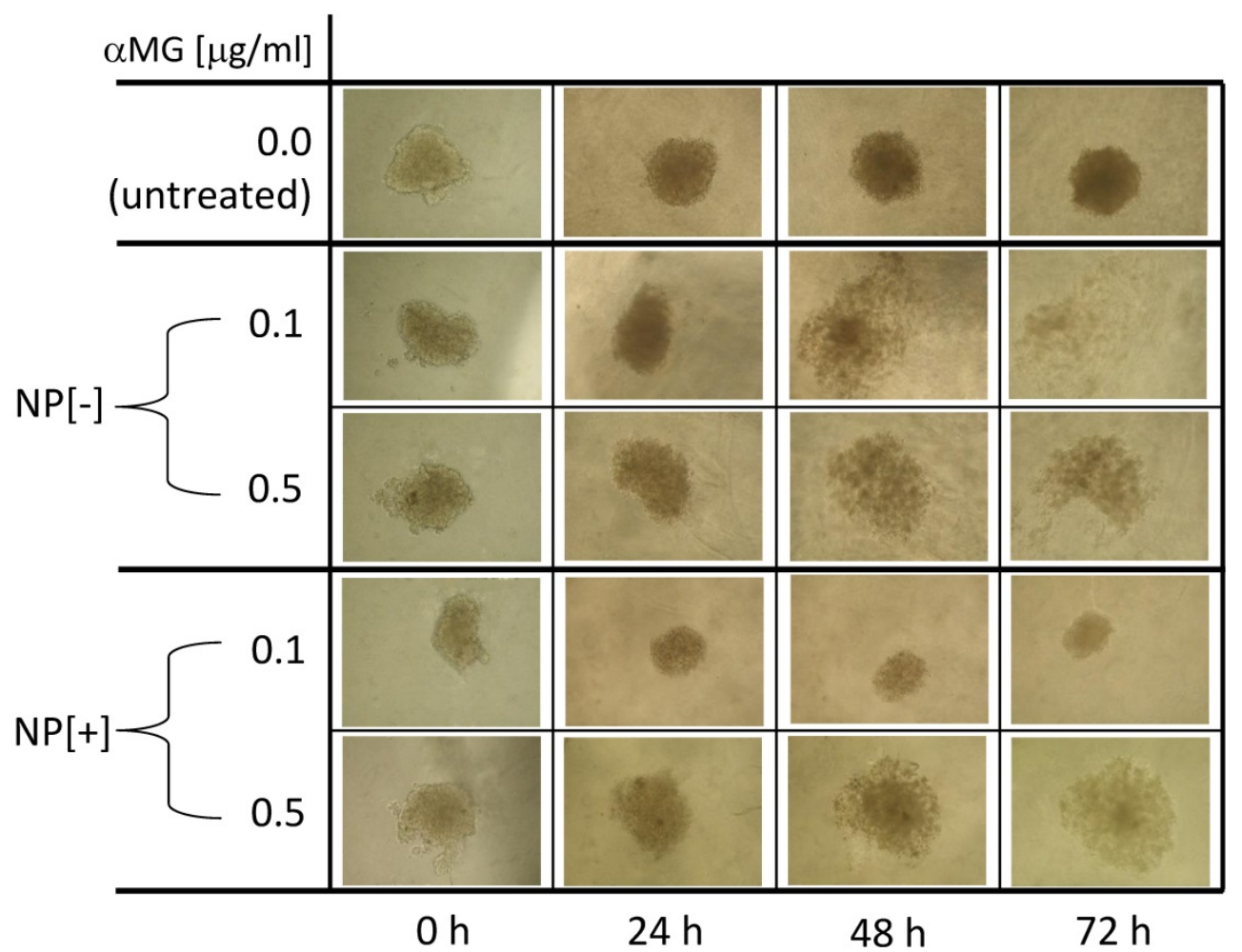

Figure 4. Morphological changes of MCTSs grown in Matrigel and treated with NPs. NPs loaded with $\alpha$ MG were able to dissociate the spheroids. MCTS treatment for 48-72 $\mathrm{h}$ with NPs that were not conjugated to the thioaptamer (NP[-]) and carrying 0.1 or $0.5 \mu \mathrm{g} / \mathrm{ml} \alpha \mathrm{MG}$ led to cell detachment after $48-72 \mathrm{~h}$. NPs conjugated to the thioaptamer (NP[+]) and carrying $0.1 \mu \mathrm{g} / \mathrm{ml} \alpha M G$ reduced the size of the spheroids, while NPs loaded with $0.5 \mu \mathrm{g} / \mathrm{ml} \alpha M G$ provoked MCTS disaggregation. The images are representative of two separate experiments (magnification: 50X).

The amount of $\alpha$ MG loaded in NPs was 1.4 $\mu \mathrm{g} / \mathrm{mg}$. A suspension up to $1 \mathrm{mg} / \mathrm{ml}$ of NPs without $\alpha \mathrm{MG}$ in complete medium did not affect growth and viability of cells, irrespective of the presence or absence of the thioaptamer (data not shown). 


\section{Disaggregation of MSCTs cultured in Matrigel and treated with $\alpha M G$-loaded NPs}

MCTSs were grown in Matrigel and their morphology was observed after 24, 48 and $72 \mathrm{~h}$ of treatment with NPs (Figure 4). The concentration of $0.1 \mu \mathrm{g} / \mathrm{ml} \alpha \mathrm{MG}$ carried by NPs without thioaptamer (NP[-]) was sufficient to loosen MCTS cells in a time-dependent manner. The dose of $0.5 \mu \mathrm{g} / \mathrm{ml} \alpha \mathrm{MG}$ also provoked a robust dissociation of MCTSs, independently of the absence or presence of the thioaptamer. The administration of NPs conjugated to the thioaptamer $(\mathrm{NP}[+])$ at $0.1 \mu \mathrm{g} / \mathrm{ml} \alpha \mathrm{MG}$ reduced the size of MCTSs and produced a lower effect on cell aggregation.

\section{Disaggregation of MSCTs cultured in gelatine and treated with $\alpha M$ M-loaded NPs}

aMG conveyed by NPs caused the disaggregation of MCTSs also when they were grown in gelatine (Figure 5). An initial drop in spheroid density was observed just after $24 \mathrm{~h}$ of treatment with $0.1 \mu \mathrm{g} / \mathrm{ml}$ aMG. Maximal spheroid dissociation was obtained using NPs with $0.5 \mu \mathrm{g} / \mathrm{ml} \alpha \mathrm{MG}$ for $72 \mathrm{~h}$, as it was shown by the lowest density and the highest area of the MCTSs. The presence of the thioaptamer linked to NPs $(\mathrm{NP}[+])$ attenuated the MCTS expansion after treatment with $1.0 \mu \mathrm{g} / \mathrm{ml} \alpha \mathrm{MG}$ for $48 \mathrm{~h}(\mathrm{p}<0.01)$ and $72 \mathrm{~h}(\mathrm{p}<0.05)$, as it was shown by the lower values of the area relative to NP[-]. However, the reduction in density produced by $\mathrm{NP}[+]$ was of the same magnitude of that obtained with NP[-] at the corresponding $\alpha \mathrm{MG}$ concentrations.
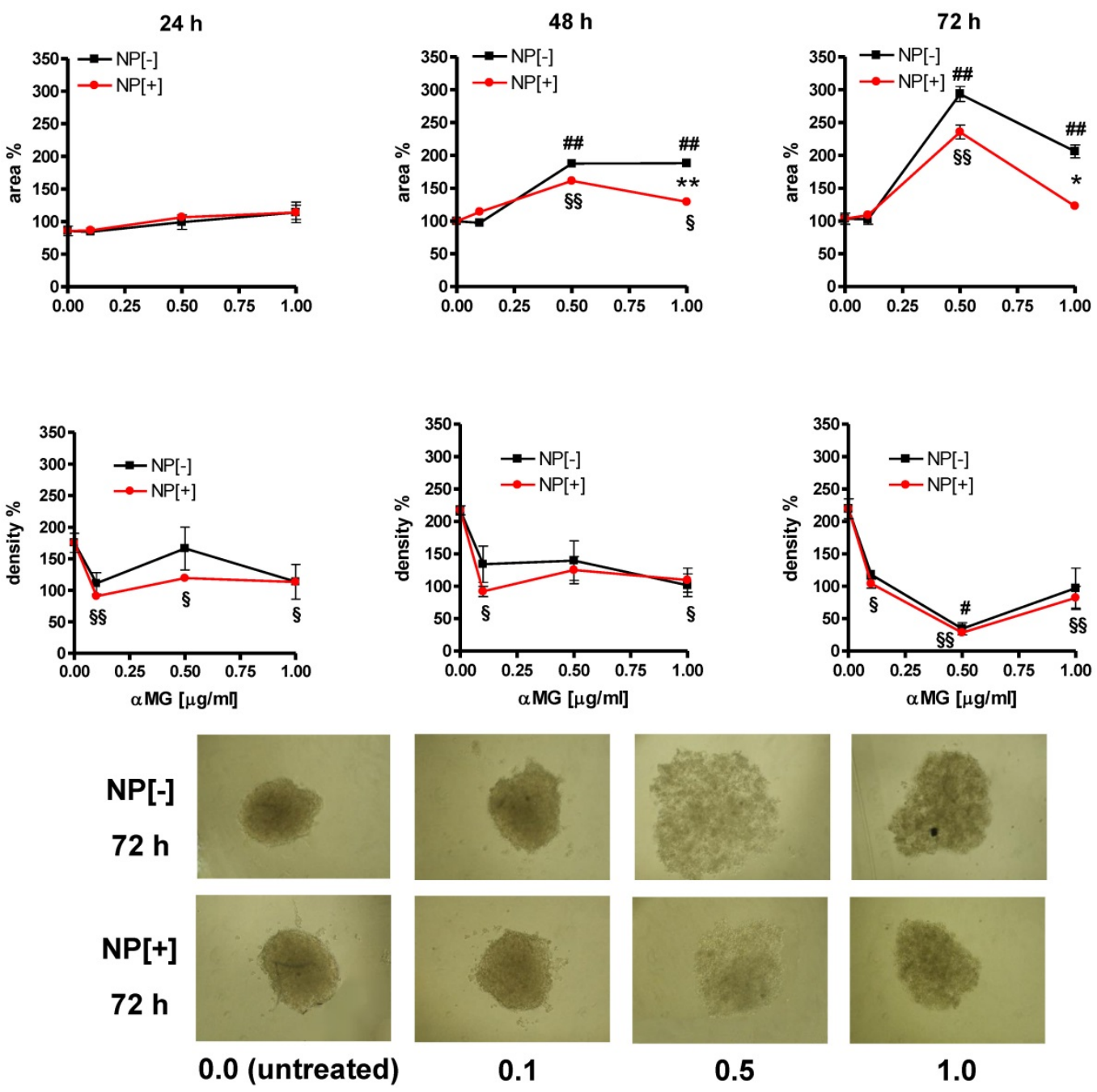

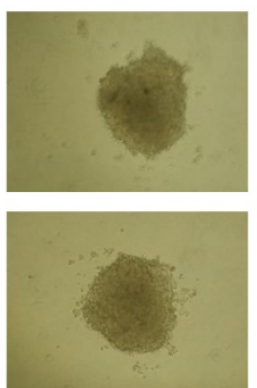

0.1
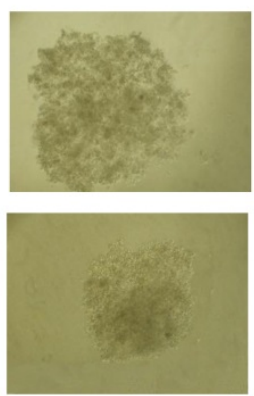

0.5
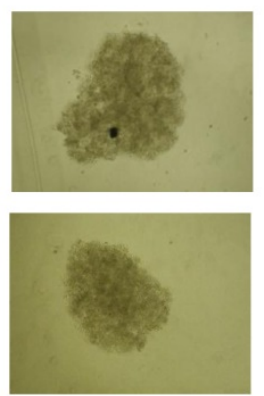

1.0

Figure 5. Morphological changes of MCTSs grown in gelatine and treated with NPs. The treatment with $\alpha$ MG-loaded NPs increased the area of MCTSs (upper slopes) and caused a parallel drop in their density (lower slopes). The lowest dose of $\alpha \mathrm{MG}$ that provoked a decrease in MCTS density was $0.1 \mu \mathrm{g} / \mathrm{ml}$ just after $24 \mathrm{~h}$ of treatment. The expansion of the area was less pronounced using NPs conjugated to the thioaptamer (NP[+]) than that caused by NPs without thioaptamer (NP[-]). $*_{p}<0.05$ and $*^{*} p<0.01$, comparing the same concentrations of $\alpha M G$ carried by NP[+] vs NP[-]. \#p $<0.05$ and \#\# $<0.01$, comparing NP[-] vs the corresponding untreated MCTSs. $\S p<0.05$ and $\$ \S_{p}<0.01$, comparing NP[+] vs the corresponding untreated MCTSs. Micrographs show the dramatic changes of MCTS morphology after treatment with NPs at concentrations of $\alpha M G$ up to $1.0 \mu \mathrm{g} / \mathrm{ml}$ delivered for $72 \mathrm{~h}$ (magnification: $50 \mathrm{X}$ ). The numerical values under the images are concentrations of $\alpha M G$ expressed as $\mu \mathrm{g} / \mathrm{ml}$. 

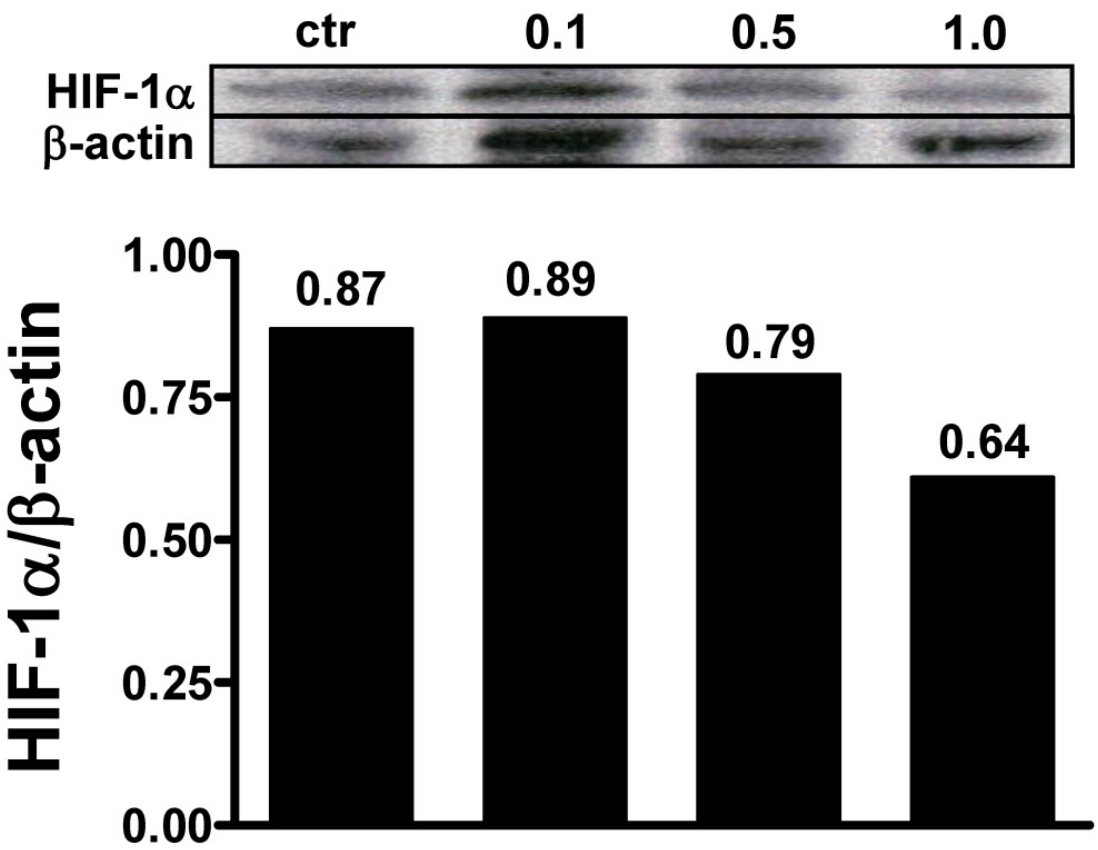

Figure 6. Effects of NPs on HIF-1 $\alpha$ cellular levels. MCF-7 cells were exposed to $1 \% \mathrm{O}_{2}$ and the presence of HIF-1 $\alpha$ was evaluated after treatment with $\alpha$ MG-loaded NPs. The administration of $0.1 \mu \mathrm{g} / \mathrm{ml} \alpha \mathrm{MG}$ for $48 \mathrm{~h}$ was not sufficient to reduce the amount of HIF-1 $\alpha$, while $0.5-1.0 \mu \mathrm{g} / \mathrm{ml} \mathrm{provoked} \mathrm{a} \mathrm{decrease} \mathrm{of} \mathrm{its} \mathrm{levels.} \mathrm{The} \mathrm{figure}$ shows representative lanes with corresponding densitometric measurements of duplicated experiments.

\section{Reduced levels of HIF-1 $\alpha$ after treatment with $\alpha M G$}

MCF-7 cell monolayers were exposed to $1 \% \mathrm{O}_{2}$ tension for $48 \mathrm{~h}$ and the ability of $\alpha \mathrm{MG}$ to affect the intracellular levels of hypoxia-induced factor- $1 \alpha$ (HIF-1 $\alpha$ ) was investigated. Under these conditions, it was possible to detect HIF-1 $\alpha$ by western blot and to assess that $0.5 \mu \mathrm{g} / \mathrm{ml}$ and $1.0 \mu \mathrm{g} / \mathrm{ml} \quad \alpha \mathrm{MG}$ encapsulated into NPs reduced its cellular concentrations in a dose-dependent manner (Figure 6), irrespective of the absence or presence of the thioaptamer. Similar effects were also obtained using free $\alpha \mathrm{MG}$ at the concentrations of $0.5 \mu \mathrm{g} / \mathrm{ml}$ and 1.0 $\mu \mathrm{g} / \mathrm{ml}$ (data not shown).

\section{Discussion}

In the present study, we evaluated the ability of NPs containing $\alpha$ MG to cause damage to MCF-7 cells grown in 3D as MCTSs. A robust derangement of spheroids was evidenced by the irregular shape of their edge accompanied by a parallel dissociation and decrease in density of the tumour bulk. The augmented distance between cells that was observed after treatment with $\alpha$ MG-loaded NPs did not occur only at the periphery of the MCTSs but also in the innermost layers, indicating that this effect of $\alpha \mathrm{MG}$ was extended to the overall volume of the spheroid. The antitumor activity of $\alpha$ MG delivered by NPs was investigated using MCTSs growing in Matrigel or gelatine. Both gels are usually employed to simulate the ECM of MCTSs but with different analytical end-points for tumour aggressiveness investigations. Specifically, Matrigel provides a suitable support for tumour invasion assays, while gelatine is a better substrate to evaluate cell migration resembling cell dissemination from a solid microtumour or micrometastases [21].

In our recent study [3], we underlined that $\alpha \mathrm{MG}$ was able to dissociate MCSTs generated by MDA-MB-231 breast cancer cells without increasing their tendency to migrate in a gelatine environment. The cells of these spheroids even reduced their motility when exposed to $\alpha \mathrm{MG}$, an antitumor effect that was also demonstrated in carcinomas deriving from other tissues [22, 23]. We also reported that MCF-7 cells of MCTSs could not migrate in gelatine-coated plates because of the low aggressiveness of this breast cancer cell line. In the present study, the spheroids cultured on Matrigel- or gelatine-coated plates significantly reduced their compactness after treatment with aMG-loaded NPs but did not show any sign of invasiveness. The lack of invadopodia conferring a characteristic "starburst" pattern to MCTSs was a further confirmation that the looser aggregation of cells was not paralleled by an increase in malignancy. Therefore, the detachment of cells from MCTSs caused the by $\alpha$ MG-loaded NPs can be really considered a significant anticancer effect that is not accompanied by the risk of increased invasiveness or metastatic spreading.

The lowest concentration of $\alpha \mathrm{MG}$ as a cargo of NPs that provoked a substantial reduction in spheroid 
density in the presence of gelatine was $0.1 \mu \mathrm{g} / \mathrm{ml}$ and the greatest disaggregation was obtained with 0.5 $\mu \mathrm{g} / \mathrm{ml} \alpha \mathrm{MG}$. It is worth noting that these doses of $\alpha \mathrm{MG}$ delivered by NPs are about tenfold inferior to those provoking damages to MCF-7 MCTSs with free $\alpha$ MG. Moreover, $\alpha$ MG delivered by NPs dissociated MCTSs that were cultured in Matrigel or gelatine. Thus, these results suggest that: (i) NPs are suitable vehicles allowing $\alpha \mathrm{MG}$ to damage tumours at very low concentrations; (ii) the $\alpha \mathrm{MG}$-dependent loss of contacts shown by MCF-7 MCTS cells involves the presence of a gel containing collagen fibres. The finding that $\alpha \mathrm{MG}$ can inhibit the adhesion of MCF-7 cells to type I collagen [24] supports the hypothesis that some components of the ECM are involved in the dissociation of MCTSs induced by the xanthone. It has been also reported that an inadequate contact of collagen to integrins $\beta$ represented an early step blunting the FAK/Akt/ERK cascade that, in turn, provoked the downregulation of the NF-kB-driven expression of MPP2 and MPP9 metalloproteinases [25]. This last effect is considered one important mechanism responsible for the reduced invasiveness of tumour cells that follows a treatment with $\alpha \mathrm{MG}$ [25]. Moreover, Kopp et al. demonstrated that the capability of MCF-7 cells to form MCTSs was related to the activity of NF-kB [26]. Thus, we supposed that the anti-adhesive property shown by $\alpha$ MG-loaded NPs towards breast cancer MCTSs was the result of the weaker bond that MCF-7 cells established with collagen fibres inside the spheroid and the consequent lack of NF-kB activation. Similarly, Ivascu at al. showed that an anti-integrin $\beta 1$ antibody was able to dissociate MDA-MB-231 spheroids exclusively when they were grown in the presence of 2.5\% Matrigel [27]. It is presumably that also under our conditions both Matrigel and gelatine fibres contributed to the supporting network of the growing MCTSs and that $\alpha \mathrm{MG}$ counteracted some cellular activity related to the presence of collagen. Moreover, Ivascu et al. demonstrated that the dissociation of MCTSs did not imply the loss of viability of tumour cells [27]. Therefore, the use of low doses of $\alpha$ MG-loaded NPs could be investigated as a non-toxic adjuvant drug for tumour chemotherapy. Indeed, the aMG-driven cell dissociation might facilitate both penetration and diffusion of conventional drugs into the tumour bulk.

When $\alpha$ MG was delivered by the NPs conjugated to the CD44 thioaptamer, a loss in cell contact of tumour spheroids did also occur, but MCTSs underwent a lower size in respect to those obtained with NPs not linked to the thioaptamer. This suggests that a number of cells died or slowed down their process of duplication. To explain this effect, it is important to underline that at least $60 \%$ of MCF-7 cells express CD44 [28] and that these cells, by sequestering via a very efficient receptor-mediated process the aMG-loaded NPs conjugated to the thioaptamer, should be subjected to a more severe antitumor activity.

Several molecular mechanisms underlying the aMG action have been described, including the inhibition of HIF-1 $\alpha$ in pancreatic stellate cells [29]. In the present study, we also observed that $\alpha \mathrm{MG}$ was able to downregulate the protein expression of HIF-1 $\alpha$ in MCF-7 cell monolayers after hypoxia activation. Thus, as previously suggested [30], it is conceivable that $\alpha \mathrm{MG}$ can reduce the number of cancer cells that have been adapted to hypoxia by blunting the expression of HIF-1 $\alpha$. It is interesting to note that breast epithelial CSCs, which are protected from drug toxicity in their hypoxic "niches", largely express CD44 together with the epithelial-specific antigen

(ESA), whilst they stain CD24-/low [31]. Consequently, NPs bearing $\alpha \mathrm{MG}$ and targeting CD44+ cells could represent a drug able to target both CSCs and cells of the tumour bulk in breast carcinoma. In addition, the clinic-pathological and adverse prognostic implications of the expression of HIF- $1 \alpha$ that have been demonstrated in different cancer types $[32,33]$ reinforce the expectation towards the antitumor efficacy of drugs targeting HIF- $1 \alpha$.

Another advantage of NPs conjugated to a thioaptamer, rather than a normal aptamer, should be their lower clearance due to the elevated resistance that the sulphur-adenine nucleotides offer against the nuclease attack [34]. Moreover, the PLGA core of the NPs used in the present study was covered by phospholipids and PEG that have been demonstrated to increase their in vivo lifespan [11].

In conclusion, these results underlines how great is the antitumor effect of $\alpha \mathrm{MG}$ delivered by lipidic NPs, since very low concentrations of the xanthone as a cargo caused a strong disaggregation of MCF-7 MCTSs. When aMG was loaded in CD44 thioaptamer-tagged NPs, it was still responsible of spheroid dissociation, but the toxic effect was more relevant because accompanied by a reduction in MCTS size. Studies are in progress to ascertain whether the selectivity of $\alpha \mathrm{MG}$-loaded NPs linked to a CD44 thioaptamer may also represent a strategy to destroy CSCs in breast carcinomas.

\section{Abbreviations}

aMG: $\alpha$-mangostin; b-FGF: basic fibroblast growth factor; DMEM: Dulbecco's modified Eagle medium; ECACC: The European Collection of Authenticated Cell Culture; EGF: epidermal growth factor; ESA: epithelial-specific antigen; MCTS: 
multicellular tumour spheroid; ULA: ultra-low attachment.

\section{Acknowledgments}

This study was financially supported by: 1) Fondazione del Monte di Bologna e Ravenna (Italy), project "Selective destruction of hypoxic cancer stem cells by bifunctional nanoparticles" and 2) University of Bologna (Italy), budget from "Ricerca Fondamentale Orientata".

\section{Authors' contributions}

F. Bonafè, C. Pazzini: concept/design/ acquisition of data, data analysis/interpretation.

S. Marchionni: SEM analysis, critical revision of the manuscript.

C. Guarnieri: critical revision of the manuscript.

C. Muscari (principal investigator): concept/ design/acquisition of data, data analysis/ interpretation, drafting of the manuscript, critical revision of the manuscript.

\section{Competing Interests}

The authors have declared that no competing interest exists.

\section{References}

1. Chen G, Li Y, Wang W, et al. Bioactivity and pharmacological properties of a-mangostin from the mangosteen fruit: a review. Expert Opin Ther Pat. 2018; 28: 415-27.

2. Zhang KJ, Gu QL, Yang K, et al. Anticarcinogenic effects of a-mangostin: A review. Planta Med. 2017; 83: 188-202.

3. Scolamiero G, Pazzini C, Bonafè F, et al. Effects of a-Mangostin on Viability, Growth and Cohesion of Multicellular Spheroids Derived from Human Breast Cancer Cell Lines. Int J Med Sci. 2018; 15: 23-30.

4. Huang BW, Gao JQ. Application of 3D cultured multicellular spheroid tumor models in tumor-targeted drug delivery system research. J Control Release. 2018; 270: 246-59.

5. Elliott NT, Yuan F. A review of three-dimensional in vitro tissue models for drug discovery and transport studies. J Pharm Sci. 2011; 100: 59-74.

6. Langan LM, Dodd NJF, Owen SF, et al. Direct Measurements of Oxygen Gradients in Spheroid Culture System Using Electron Paramagnetic Resonance Oximetry. PLoS ONE. 2016; 11: e0149492. doi:10.1371/journal.pone.0149492

7. Reynolds DS, Tevis KM, Blessing WA, et al. Breast Cancer Spheroids Reveal a Differential Cancer Stem Cell Response to Chemotherapeutic Treatment. Sci Rep. 2017; 7: 10382. doi:10.1038/s41598-017-10863-4.

8. Bonafè F, Guarnieri C, Muscari C. Cancer stem cells and mesenchymal stem cells in the hypoxic tumor niche: two different targets for one only drug. Med Hypotheses. 2015; 84: 227-30.

9. Charoen KM, Fallica B, Colson YL, et al. Embedded multicellular spheroids as a biomimetic 3D cancer model for evaluating drug and drug-device combinations. Biomaterials. 2014; 35: 2264-71.

10. Cruz AF, Fonseca NA, Moura V, et al. Targeting cancer stem cells and non-stem cancer cells: the potential of lipid-based nanoparticles. Curr Pharm Des. 2017; [Epub ahead of print].

11. Chan JM, Zhang L, Yuet KP, et al. PLGA-lecithin-PEG core-shell nanoparticles for controlled drug delivery. Biomaterials. 2009; 30: 1627-34

12. Kobayashi H, Watanabe R, Choyke PL. Improving conventional enhanced permeability and retention (EPR) effects; what is the appropriate target? Theranostics. 2013; 4: 81-9.

13. Xu S, Olenyuk BZ, Okamoto CT, et al. Targeting receptor-mediated endocytotic pathways with nanoparticles: rationale and advances. Adv Drug Deliv Rev. 2013; 65: 121-38.

14. Wu TT, Zhou SH. Nanoparticle-based targeted therapeutics in head-and-neck cancer. Int J Med Sci. 2015; 12: 187-200.

15. Xiang D, Zheng C, Zhou SF, et al. Superior Performance of Aptamer in Tumor Penetration over Antibody: Implication of Aptamer-Based Theranostics in Solid Tumors. Theranostics. 2015; 5: 1083-97.
16. Sahay G, Alakhova DY, Kabanov AV. Endocytosis of nanomedicines. J Control Release. 2010; 145: 182-95.

17. Le VM, Lang MD, Shi WB, et al. A collagen-based multicellular tumor spheroid model for evaluation of the efficiency of nanoparticle drug delivery. Artif Cells Nanomed Biotechnol. 2016; 44: 540-4.

18. Ivanov DP, Parker TL, Walker DA, et al. Multiplexing spheroid volume, resazurin and acid phosphatase viability assays for high-throughput screening of tumour spheroids and stem cell neurospheres. PLoS One. 2014; 9:e103817. doi: 10.1371/journal.pone.0103817.

19. Aravind A, Jeyamohan P, Nair R, et al. AS1411 aptamer tagged PLGA-lecithin-PEG nanoparticles for tumor cell targeting and drug delivery. Biotechnol Bioeng. 2012; 109: 2920-31.

20. Somasunderam A, Thiviyanathan V, Tanaka T, et al. Combinatorial selection of DNA thioaptamers targeted to the HA binding domain of human CD44. Biochemistry. 2010; 49: 9106-12.

21. Vinci M, Gowan S, Boxall F, et al. Advances in establishment and analysis of three-dimensional tumor spheroid-based functional assays for target validation and drug evaluation. BMC Biol. 2012; doi: 10.1186/1741-7007-10-29.

22. Wang JJ, Sanderson BJ, Zhang W. Significant anti-invasive activities of a-mangostin from the mangosteen pericarp on two human skin cancer cell lines. Anticancer Res. 2012; 32: 3805-16.

23. Verma RK, Yu W, Shrivastava A, et al. a-Mangostin-encapsulated PLGA nanoparticles inhibit pancreatic carcinogenesis by targeting cancer stem cells in human, and transgenic (Kras(G12D), and $\mathrm{Kras}(\mathrm{G} 12 \mathrm{D}) / \mathrm{tp} 53 \mathrm{R} 270 \mathrm{H})$ mice. Sci Rep. 2016; 6: 32743. doi: 10.1038/srep32743.

24. Lee YB, Ko KC, Shi MD, et al. alpha-Mangostin, a novel dietary xanthone, suppresses TPA-mediated MMP-2 and MMP-9 expressions through the ERK signaling pathway in MCF-7 human breast adenocarcinoma cells. J Food Sci. 2010; 75: H13-23.

25. Shih YW, Chien ST, Chen PS, et al. Alpha-mangostin suppresses phorbol 12-myristate 13-acetate-induced MMP-2/MMP-9 expressions via alphavbeta3 integrin/FAK/ERK and NF-kappaB signaling pathway in human lung adenocarcinoma A549 cells. Cell Biochem Biophys. 2010; 58: 31-44.

26. Kopp S, Sahana J, Islam T, et al. The role of NFkB in spheroid formation of human breast cancer cells cultured on the Random Positioning Machine. Sci Rep. 2018; 8: 921. doi: 10.1038/s41598-017-18556-8.

27. Ivascu A, Kubbies M. Diversity of cell-mediated adhesions in breast cancer spheroids. Int J Oncol. 2007; 31:1403-13.

28. Fillmore CM, Kuperwasser C. Human breast cancer cell lines contain stem-like cells that self-renew, give rise to phenotypically diverse progeny and survive chemotherapy. Breast Cancer Res. 2008; 10: R25. doi: 10.1186/bcr1982.

29. Lei J, Huo X, Duan W, et al. a-Mangostin inhibits hypoxia-driven ROS-induced PSC activation and pancreatic cancer cell invasion. Cancer Lett. 2014; 28 : 129-38.

30. Muscari C, Giordano E, Bonafè F, et al. Molecular mechanisms of ischemic preconditioning and postconditioning as putative therapeutic targets to reduce tumor survival and malignancy. Med Hypotheses. 2013; 81: 1141-5.

31. Zhang M, Li Z, Zhang X, Chang Y. Cancer stem cells as a potential therapeutic target in breast cancer. Stem Cell Investig. 2014; 1: 14. doi:10.3978/j.issn.2306-9759.2014.06.01.

32. Lin CS, Liu TC, Lee MT, et al. Independent Prognostic Value of Hypoxia-inducible Factor 1-alpha Expression in Small Cell Lung Cancer. Int J Med Sci. 2017; 14: 785-90.

33. Jung JH, Im S, Jung ES, et al. Clinicopathological implications of the expression of hypoxia-related proteins in gastric cancer. Int J Med Sci. 2013; 10: 1217-23

34. Micklefield J. Backbone modification of nucleic acids: synthesis, structure and therapeutic applications. Curr Med Chem. 2001; 8: 1157-79. 